\title{
Advanced Systems for Public Transport
}

\author{
Juan Carlos Muñoz
}

C Springer-Verlag Berlin Heidelberg 2013

It is our pleasure to introduce this issue from Public Transport with a selected set of the papers that were presented at the 12th Conference of Advanced Systems for Public Transport (CASPT12) held by the Department of Transport Engineering and Logistics of the Pontificia Universidad Católica de Chile and its Bus Rapid Transit Centre of Excellence in Santiago, Chile on July 23-27 2012.

CASPT has become the most important conference in the field of design and operations of public transport systems and serves as a forum for the international community of researchers, practitioners and vendors involved in all aspects of public transport planning and operations (with similar emphasis in bus and rail based services). CASPT covers significant contributions to the theory and application of systems and methodologies for advancing public transport planning and operations. CASPT encourages not only the generation and presentation of new ideas, but also hopes to instigate productive collaborations between participants from academia, industry, and government.

This version of CASPT was the 12th in the series, and for the first time it was organized in the southern hemisphere and in Latin America. Latin America is very active regarding modernizing the public transport sector, as can be observed in the successful blend between urban planning and transit development in Curitiba, Brasil or in the innovative and amazingly productive Bus Rapid Transit network operating in Bogotá, Colombia. These systems have inspired the world. Santiago also offers a very interesting system with full integration between buses and Metro and a $100 \%$ penetration of a touchless card payment device. Transantiago, as the system is called, has very significant achievements, but also has faced severe problems. Both can be easily observed, and from which CASPT attendants learned during the meeting.

J.C. Muñoz (凶)

Santiago, Chile

e-mail: jcm@ing.puc.cl 
Also, we managed to have the recently formed Latinamerican Association of Integrated Public Transport Systems and BRT, SIBRT, to run a meeting of their agencies in parallel to CASPT. Finally, a fair of some of the most relevant software providers for managing, designing and control of public transport systems was organized during the event. These companies were very active in the beginnings of the CASPT series, and at CASPT12 they got back to a central position. By the end of the conference, a workshop was organized where CASPT attendants interacted with software providers in an open discussion about the evolution of the industry, the interaction with academia and the needs for the coming years. This blend created a quite unique interaction between members of transit agencies and operators, software providers and the more traditional CASPT academic community.

We would like to express our gratitude to the International Scientific Committee for giving us the opportunity to host CASPT, and to the organizations and sponsors whose financial contribution and support have made it possible to host the 12th CASPT in Chile.

The event captured the attention of researchers worldwide; over 180 contributions were received, 95 of which were presented at CASPT12. These 95 papers involved researchers from 35 countries of the five continents. This special issue presents a selection of some of the best contributions to the Conference. Some additional papers will appear in a future issue of Public Transport, too.

The focus of the included papers spreads over the whole potpourri of topics in public transport and public mass transit. Beyond the consideration of issues on, for instance, bus service design and railway traffic management we also see topical extensions towards ground movements at airports as well as methodological advances like rapid branching applied to public transport operations problems.

On behalf of the Organizing Committee of CASPT12 as well as the editors of Public Transport. 